\title{
The role of cGMP-cGKI-signaling for duodenal bicarbonate
} secretion

\author{
Beate Spiessberger*1, Pascal Weinmeister ${ }^{1}$, Franz Hofmann ${ }^{1}$, \\ Claudia Werner ${ }^{1}$, Dieter Saur ${ }^{2}$, Ursula Seidler ${ }^{3}$, Wen Zheng ${ }^{3}$, \\ Jens Schlossmann ${ }^{4}$ and Robert Lukowski ${ }^{1,5}$
}

\begin{abstract}
Address: ${ }^{1}$ For 923 at Institut für Pharmakologie und Toxikologie, TU München, Germany, ${ }^{2}$ Department of Internal Medicine II, Klinikum Rechts der Isar, TU München, Germany, ${ }^{3}$ Department of Gastroenterology, Hepatology and Endocrinology, Hannover Medical School, Germany,

${ }^{4}$ Department of Pharmacology and Toxicology, Universität Regensburg, Germany and ${ }^{5}$ Institut für Pharmakologie und Toxikologie, TU München, Germany

Email: Beate Spiessberger* - spiessberger@ipt.med.tu-muenchen.de

* Corresponding author
\end{abstract}

from 4th International Conference of cGMP Generators, Effectors and Therapeutic Implications

Regensburg, Germany. 19-21 June 2009

Published: II August 2009

BMC Pharmacology 2009, 9(SuppI I):P67 doi:I0.1 I86/I47I-2210-9-SI-P67

This abstract is available from: http://www.biomedcentral.com/I47I-22/0/9/SI/P67

(c) 2009 Spiessberger et al; licensee BioMed Central Ltd.

\section{Background}

The duodenal mucosa protects itself from gastric acid injury by the secretion of bicarbonate from epithelial cells. We determined a possible role of the cGMP-cGKI pathway for the duodenal bicarbonate secretion by studying conventional cGKI knockouts (cGKI-KOs) and rescue mice (RM) that express either the CGKI $\alpha$ or I $\beta$ isoform in SM22 $\alpha$ positive smooth muscle cells [1].

\section{Results}

The basal secretion rate of bicarbonate was strongly reduced in the different gene-targeted cGKI mice. Moreover, the $\mathrm{H}^{+}$induced bicarbonate secretion was significantly increased in controls but nearly absent in all cGKI mutants, whereas invasive $\mathrm{pH}$ measurements in fasted animals demonstrated that the gastric acid production of all genotypes was similar. The dysfunction of the duodenal bicarbonate secretion of RM and cGKI-KO animals was associated with severe gastrointestinal bleedings, which were caused by the age-dependent aggravation of an epithelial ulceration that localized to the papilla Vateri.

\section{Conclusion}

The analysis of cGKI-KO and RM indicates that a cGMPcGKI-dependent pathway is present in non-smooth mus- cle cells of the duodenum that is involved in the basal and acid-induced secretion of bicarbonate. The inability to secrete adequate amounts of bicarbonate ultimately leads to duodenal ulceration. We postulate that the continuous blood loss accounts for the chronic anemia of cGKI mutant mice and causes the premature death of the cGKIKOs and RM.

\section{Acknowledgements}

We greatly thank Teodora Ruttner for her skilled technical support.

\section{References}

I. Weber S, Bernhard D, Lukowski R, Weinmeister P, Wörner R, Wegener JW, Valtcheva N, Feil S, Schlossmann J, Hofmann F, Feil R: Rescue of cGMP kinase I knockout mice by smooth muscle specific expression of either isozyme. Circ Res 2007, I01:1096-103. 